\title{
Aberrant promoter methylation of cancer-related genes in human breast cancer
}

\author{
LIANG WU $^{1 *}$, YE SHEN $^{2 *}$, XIANZHEN PENG ${ }^{1}$, SIMIN ZHANG $^{1}$, MING WANG $^{1}$, \\ GUISHENG XU ${ }^{1}$, XIANZHI ZHENG ${ }^{1}$, JIANMING WANG ${ }^{1,3,4}$ and CHENG LU ${ }^{5}$ \\ ${ }^{1}$ Department of Epidemiology, School of Public Health, Nanjing Medical University, Nanjing, Jiangsu 211166; \\ ${ }^{2}$ Department of Gastrointestinal Surgery, Aoyoung Hospital, Zhangjiagang, Jiangsu 215617; \\ ${ }^{3}$ Department of Social Medicine and Health Education, School of Public Health, Nanjing Medical University; \\ ${ }^{4}$ The Innovation Center for Social Risk Governance in Health, Nanjing, Jiangsu, 211166; ${ }^{5}$ Department of Breast, \\ Nanjing Maternity and Child Health Hospital of Nanjing Medical University, Nanjing, Jiangsu 210004, P.R. China
}

Received June 10, 2015; Accepted October 18, 2016

DOI: $10.3892 / \mathrm{ol} .2016 .5351$

\begin{abstract}
The clinical relevance of aberrant DNA methylation is being increasingly recognized in breast cancer. The present study aimed to evaluate the promoter methylation status of seven candidate genes and to explore their potential use as a biomarker for the diagnosis of breast cancer. A total of 70 Chinese patients with breast cancer were recruited, and matched with 20 patients with benign breast disease (BBD). Methylation-specific polymerase chain reaction was performed to measure the methylation status of selected genes. The protein expression of candidate genes was determined by immunohistochemistry. Hypermethylation of Breast cancer 1, early onset; DNA repair associated (BRCA1), glutathione S-transferase pi 1 (GSTP1), cyclin dependent kinase inhibitor 2A, O-6-methylguanine-DNA methyltransferase, phosphatase and tensin homolog, retinoic acid receptor beta 2 and cyclin D2 was observed to be more common in cancerous tissues $(24.3,31.4,40.0,27.1,48.6,55.7$ and $67.1 \%$, respectively) as compared with BBD controls $(0.0,0.0,20.0,25.0,40.0$, 40.0 and $45.0 \%$, respectively). Immunohistochemical analysis demonstrated a correlation between the methylation of the target gene and downregulation of protein expression. When BRCA1 and GSTP1 were combined as the biomarker, the area
\end{abstract}

Correspondence to: Professor Jianming Wang, Department of Epidemiology, School of Public Health, Nanjing Medical University, 101 Longmian Avenue, Nanjing, Jiangsu 211166, P.R. China E-mail: jmwang@njmu.edu.cn

Dr Cheng Lu, Department of Breast, Nanjing Maternity and Child Health Hospital of Nanjing Medical University, 123 Tianfeixiang, Mochou Road, Nanjing, Jiangsu 210004, P.R. China

E-mail: lucheng66@126.com

*Contributed equally

Key words: breast cancer, benign breast disease, hypermethylation, molecular epidemiology, diagnosis under the receiver operating characteristic curve reached 0.721 (95\% confidence interval, 0.616-0.827). The present findings indicated that promoter methylation of cancer-related genes was frequently observed in patients with breast cancer and was associated with various clinical features. Hypermethylation of BRCA1 and GSTP1 may be used as promising biomarkers for breast cancer.

\section{Introduction}

Breast cancer (BC) is one of the most common cancers in women worldwide. It is estimated that $>508,000$ women succumbed to BC in 2011 (1). Although BC used to be a common disease in the developed world, recently $\sim 50 \%$ of new cases and $58 \%$ of deaths have occurred in less developed countries (1). Localized BC at an early stage has an improved prognosis and requires less severe treatment with a survival rate of $98 \%$. However, diagnosis after tumor metastasis significantly reduces the survival rate to $27 \%$ (2). Early detection may greatly improve the prognosis of patients with BC. Screening through mammography has shown a significant reduction of mortality through the early detection of disease (3). However, its sensitivity and specificity remain dissatisfactory (2). False-positive results are more common for younger women, women who have had previous breast biopsies, women with a family history of $\mathrm{BC}$ and women who are taking estrogen $(4,5)$. Molecular biomarkers are novel methods of indirect and direct detection of $\mathrm{BC}$.

Epigenetic alteration is one of the most common molecular changes identified in the progression of human cancer $(6,7)$. Epigenetic mechanisms include aberrant DNA methylation, changes in histone and chromatin structure by post-translational modification of histone proteins and alterations in the expression of microRNAs (8). Aberrant DNA methylation may alter normal gene expression, genomic structure and genetic stability (9). It is well established that widespread changes of DNA methylation occur during carcinogenesis and tumor progression (10). Distinct from other biomarkers in BC which are typically based on gene expression, DNA methylation has been identified to have independent prognostic values that can 
be used in tailoring treatment to patients who are receiving uniform therapy regimens (11).

Promoter methylation predominantly follows a tumor-specific pattern and has been reported to be a useful biomarker in various types of cancer, including invasive BC (12). Previous studies have shown the frequent methylation of genes involved in cell cycle regulation [cyclin dependent kinase inhibitor $2 \mathrm{~A}\left(P 16^{\mathrm{INK} 4 \mathrm{~A}}\right)$, ARF tumor suppressor, cyclin dependent kinase inhibitor 2B, cyclin D2 (CCDN2) and death associated protein kinase $1(D A P K)]$, DNA repair [O-6-methylguanine-DNA methyltransferase (MGMT) and MutL homolog 1], xenobiotic metabolism [glutathione S-transferase pi $1(G S T P 1)$ ], signal transduction [retinoic acid receptor beta $2(R A R \beta 2)$, WNT signaling pathway regulator $(A P C)$ and estrogen receptor $2(E R \beta)]$, adhesion and metastasis (cadherin 1 and cadherin 13) in BC (13-16). As these alterations occurred in cancer tissues at a higher frequency, they are potentially useful biomarkers for detecting cancer (17). Using promoter methylation of a panel of common cancer-related genes can discriminate normal and cancer tissues with a promising sensitivity and specificity (18). Since BC is heterogeneous, methylation status and the type of genes remain discordant among different studies (18). Therefore the true frequency and utility of DNA methylation as a biomarker in $\mathrm{BC}$ has yet to be established (12).

In order to search for a reliable gene panel for detecting $\mathrm{BC}$, the present study qualitatively assessed the methylation frequency of seven candidate genes [breast cancer 1, early onset; DNA repair associated (BRCA1), GSTP1, P16 ${ }^{\mathrm{INK} 4 \mathrm{~A}}$, $M G M T$, phosphatase and tensin homolog (PTEN), RAR $\beta 2$ and $C C N D 2)$ and their protein expression in a Chinese population.

\section{Materials and methods}

Ethical statement. The Institutional Review Board of Nanjing Medical University (Nanjing, China) approved the study. Written informed consent was obtained from all individual participants included in the study.

Patients and specimens. A total of 70 female patients with BC (age range, 32-93 years; median age, 54.5 years) were recruited from the First People's Hospital of Zhenjiang City (Zhenjiang, China) between April 2012 and December 2014. Patients were diagnosed via pathological evidence. Tumor stage was determined according to the Classification of Malignant Tumors Staging System (TNM) (19). To investigate the diagnostic value of DNA methylation in BC, 20 patients with benign breast diseases (BBD; age range, 20-63 years; median, 40 years) were recruited as the controls. After obtaining written informed consent from all participants, trained interviewers conducted a questionnaire to collect patient's basic characteristics and clinical information. For patients who had undergone surgery, tissues in the center of the cancer lesion and remote normal appearing breast tissue were excised and stored at $-80^{\circ} \mathrm{C}$ until the subsequent extraction of DNA. None of the enrolled patients had received preoperative chemotherapy or radiation therapy.

DNA extraction and bisulfite modification. DNA was extracted from frozen tissue using a QIAamp DNA Mini kit (Qiagen
Inc., Valencia, CA, USA) according to the manufacturer's instructions. Following quantification via NanoDrop 2000 (Thermo Fisher Scientific, Inc., Waltham, MA, USA), DNA samples were bisulphite converted and purified using the EpiTect Fast DNA Bisulfite kit (Qiagen, Inc.).

Primer design and methylation detection. CpG island methylation at the promoter region of BRCA1, GSTP1, $P 16^{\mathrm{INK} 4 \mathrm{~A}}$, $M G M T, P T E N, R A R \beta 2$ and CCND2 was determined by methylation specific polymerase chain reaction (MSP) following sodium bisulfite modification of the DNA. Prior to the analysis of the methylation status of the target genes, the presence of bisulfite modified DNA in each sample was determined by amplification of 133-bp DNA fragment of the $\beta$-actin gene, which was used for quality control (20). Modified DNA was amplified in a total volume of $25 \mu \mathrm{l}$ solution containing $0.8 \mathrm{U}$ hot-start Taq polymerase (Takara, Japan), 10X PCR buffer ( $\mathrm{Mg}^{2+}$ plus), $2.5 \mathrm{mM}$ of each dNTP, $20 \mathrm{pmol}$ of each primer and $80 \mathrm{ng}$ of bisulfite-modified genomic DNA as templates. Cycling conditions consisted of an initial denaturation step at $95^{\circ} \mathrm{C}$ for $5 \mathrm{~min}$, followed by 38 cycles of $30 \mathrm{sec}$ at $95^{\circ} \mathrm{C}, 30 \mathrm{sec}$ at the relevant annealing temperature (Table I) and $45 \mathrm{sec}$ at $72^{\circ} \mathrm{C}$. The reaction was terminated with a $10-\mathrm{min}$ extension at $72^{\circ} \mathrm{C}$. PCR products $(7-8 \mu \mathrm{l})$ were resolved on a $2.5 \%$ agarose gel containing ethidium bromide and visualized under UV illumination. To avoid the occurrance of false positive and false negative results in the reactions, each set of PCR contained positive and negative controls. Peripheral blood lymphocyte DNA treated in vitro with SssI methyltransferase (New England Biolabs, Inc., Beverly, MA, USA) was used as a positive control of methylated DNA. DNA from normal lymphocytes was used as a control of unmethylated alleles. PCR reagent without DNA template was used as a blank control. The primers were designed by Nanjing Steed BioTechnologies Co., Ltd. (Nanjing, China) (21-27).

Immunohistochemical analysis. Immunohistochemical analysis was used to evaluate the expression of specific genes in the breast tissues. Cut from the paraffin-embedded blocks using a microtome, 4- $\mu$ m-thick sections were transferred to gelatin coated slides, and dried at $56^{\circ} \mathrm{C}$ for $1 \mathrm{~h}$. Paraffin sections on slides were dewaxed in xylene twice for $15 \mathrm{~min}$ and rehydrated in a grade series of alcohol $(100,100,90,80$ and 70\%). Slides were subsequently placed in a glass jar filled with citrate buffer (0.01 M; pH 6.0) in a microwave oven for antigen retrieval and heated for $10 \mathrm{~min}$ at $97^{\circ} \mathrm{C}$. Following cooling in the jar at room temperature, the sections were treated with $3 \% \mathrm{H}_{2} \mathrm{O}_{2}$ for $20 \mathrm{~min}$ to quench the endogenous peroxidase activity. Non-specific binding was blocked with $10 \%$ goat serum (ZSJB-BIO, Beijing, China) in phosphate-buffered saline (PBS; $0.01 \mathrm{M}$; $\mathrm{pH}$ 7.4) for $30 \mathrm{~min}$ at room temperature. Without rinsing, the slides were incubated with primary antibodies against BRCA1 (MS110; ab16780; diluted 1:300 in PBS; Abcam, Cambridge, UK) and GSTP1 (3F2) (mouse monoclonal; \#3369; diluted 1:800 in PBS; Cell Signaling Technology, Inc., Danvers, MA, USA) overnight at $4^{\circ} \mathrm{C}$. For negative controls, the primary antibody was replaced by PBS. Slides were washed with PBS, followed by incubation with the horseradish peroxidase-conjugated secondary antibody (Polink-2 plus Polymer HRP Detection System; PV-9002; ZSJB-BIO) for $30 \mathrm{~min}$ at room temperature in a moist chamber. 
Table I. Summary of primer sequences, chromosomal locations, annealing temperatures and product sizes used for methylation-specific polymerase chain reaction analyses.

\begin{tabular}{|c|c|c|c|c|c|}
\hline Genes & $\mathrm{M} / \mathrm{U}$ & Sequence (5'-3') & Annealing $\left({ }^{\circ} \mathrm{C}\right)$ & Product size (bp) & Ref \\
\hline \multirow[t]{2}{*}{$\beta$-actin } & - & F: TGGTGATGGAGGAGGTTTAGTAAGT & 60.0 & 133 & 20 \\
\hline & - & R: AАCCAATAAAАССТАСТССТСССТТАA & & & \\
\hline \multirow[t]{4}{*}{$B R C A 1$} & M & F: GGTTAATTTAGAGTTTCGAGAGACG & 65.0 & 182 & 21 \\
\hline & & R: TCAACGAACTCACGCCGCGCAATCG & & & \\
\hline & $\mathrm{U}$ & F: GGTTAATTTAGAGTTTTGAGAGATG & 62.0 & 182 & \\
\hline & & R: TCAACAAACTCACACCACACAATCA & & & \\
\hline \multirow[t]{4}{*}{ GSTP1 } & M & F: TTCGGGGTGTAGCGGTCGTC & 55.0 & 91 & 22 \\
\hline & & R: GCCCCAATACTAAATCACGACG & & & \\
\hline & $\mathrm{U}$ & F: GATGTTTGGGGTGTAGTGGTTGTT & 55.0 & 97 & \\
\hline & & R: CCACCCCAATACTAAATCACAACA & & & \\
\hline \multirow[t]{4}{*}{$P 16^{I N K 4 A}$} & M & F: TTATTAGAGGGTGGGGCGGATCGC & 62.0 & 150 & 23 \\
\hline & & R: GACCCCGAACCGCGACCGTAA & & & \\
\hline & $\mathrm{U}$ & F: TTATTAGAGGGTGGGGTGGATTGT & 60.0 & 151 & \\
\hline & & R: CAACCCCAAACCACAACCATAA & & & \\
\hline \multirow[t]{4}{*}{$M G M T$} & M & F: TTTCGACGTTCGTAGGTTTTCGC & 62.0 & 81 & 24 \\
\hline & & R: GCACTCTTCCGAAAACGAAACG & & & \\
\hline & $\mathrm{U}$ & F: TTTGTGTTTTGATGTTTGTAGGTTTTTGT & 62.0 & 93 & \\
\hline & & R: AАCTCCACACTCTTCCAAAAACAAAACA & & & \\
\hline \multirow[t]{4}{*}{ PTEN } & M & F: TTCGTTCGTCGTCGTCGTATTT & 62.0 & 207 & 25 \\
\hline & & R: GCCGCTTAACTCTAAACCGCAACCG & & & \\
\hline & $\mathrm{U}$ & F: GTGTTGGTGGAGGTAGTTGTTT & 62.0 & 163 & \\
\hline & & R: ACCACTTAACTCTAAACCACAACCA & & & \\
\hline \multirow[t]{4}{*}{$R A R \beta 2$} & M & F: TCGAGAACGCGAGCGATTCG & 62.0 & 146 & 26 \\
\hline & & R: GACCAATCCAACCGAAACGA & & & \\
\hline & $\mathrm{U}$ & F: TTGAGAATGTGAGTGATTTGA & 60.5 & 146 & \\
\hline & & R: AACCAATCCAACCAAAACAA & & & \\
\hline \multirow[t]{4}{*}{$C C N D 2$} & $\mathrm{M}$ & F: TCGGTGTGGTTACGTTTAGC & 59.0 & 160 & 27 \\
\hline & & R: TAAAACGACGCGATACAACG & & & \\
\hline & $\mathrm{U}$ & F: TGGTGTGGTTATGTTTAGTG & 59.0 & 150 & \\
\hline & & R: ACAATACAACATCTAAAACCAC & & & \\
\hline
\end{tabular}

M, methylated primer; $\mathrm{U}$, unmethylated primer; F, forward primer; R, reverse primer; $B R C A 1$, breast cancer 1, early onset; DNA repair associated; GSTP1, glutathione S-transferase pi 1; $P 16^{I N K 4 A}$, cyclin dependent kinase inhibitor 2A; MGMT, O-6-methylguanine-DNA methyltransferase; PTEN, phosphatase and tensin homolog; $R A R \beta 2$, retinoic acid receptor beta 2; CCND2, cyclin D2.

The chromogenic reaction was visualized by diaminobenzidine and counterstained with hematoxylin. Finally, cells were gradually dehydrated with graded ethanol and sealed with neutral gum. Images were captured using an upright fluorescence microscope (Eclipse 80i; Nikon Corporation, Tokyo, Japan).

Immunohistochemical results were scored independently by two pathologists who were blind to the methylation status of the samples. The expression of BRCAI and GSTPI was evaluated using the semi-quantitative scoring criteria according to the staining intensity ( 0 , negative; 1 , weak; 2 , moderate; and 3, strong) and the proportion of positive cells ( 0 , positive in $\leq 5 \%$; 1 , positive in $>5$ and $\leq 25 \%$; 2 , positive in $>25$ and $\leq 50 \%$; 3 , positive in $>50$ and $\leq 80 \%$; and 4 , positive in $>80 \%$ tumor cells). The two scores were multiplied together for each case and gene expression was subsequently graded as: 0 , negative score; $1-4$, weak expression score; $5-8$, moderate expression score; and 9-12, strong expression score (28).
Statistical analysis. Pearson's $\chi^{2}$ or Fisher's exact test were used to compare clinicopathological features between cases and controls. Mann-Whitney U testing was used for nonparametric distributed variables. Discriminant validity of selected genes was examined using the receiver operating characteristic (ROC) curve. Sensitivity, specificity, and the area under the curve (AUC) were calculated. $\mathrm{P}<0.05$ was considered to indicate a statistically significant difference. All statistical analyses were performed using SPSS 18.0 (SPSS, Inc., Chicago, IL, USA) or STATA 12.0 (Stata Corporation, College Station, TX, USA).

\section{Results}

Promoter methylation in $B C$ and $B B D$. A total of 70 patients with $\mathrm{BC}$ (age range, 32-93 years; median age, 54.5 years) and 20 patients with BBD (age range, 20-63 years; 


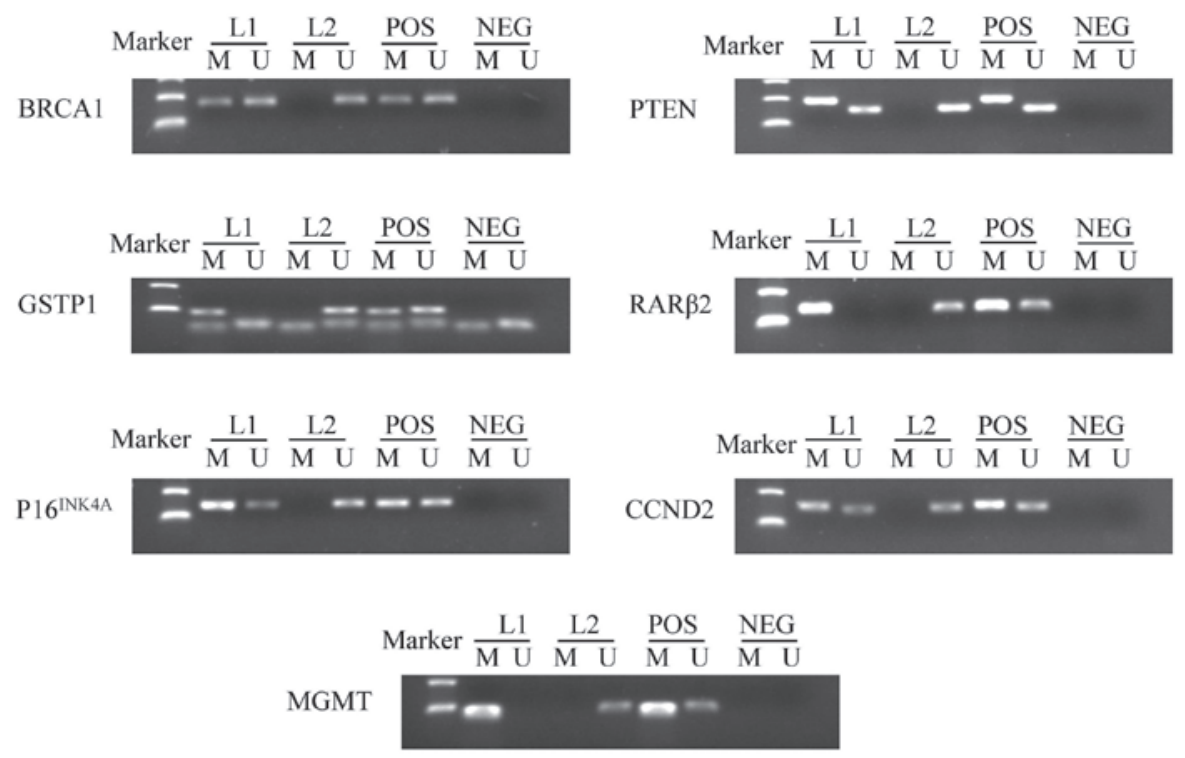

Figure 1. Representative results of methylation-specific polymerase chain reaction analyses. Peripheral blood lymphocytes DNA treated by SssI methyltransferase was used as the methylation-positive control and DNA from normal lymphocytes was used as the unmethylation-positive control. NEG, negative control; Lane L1-L2, breast cancer samples; M, methylation; U, unmethylation; POS, positive control; BRCA1, breast cancer 1, early onset; DNA repair associated; GSTP1, glutathione S-transferase pi 1; P16 INKAA cyclin dependent kinase inhibitor 2A; MGMT, O-6-methylguanine-DNA methyltransferase; PTEN, phosphatase and tensin homolog; $R A R \beta 2$, retinoic acid receptor beta 2; $C C N D 2$, cyclin D2.

median, 40 years) were enrolled. The majority of patients with $\mathrm{BC}$ were diagnosed with invasive ductal carcinoma (82.9\%) and $55.7 \%$ were defined as stage II. For BBD patients, the majority were diagnosed with fibroadenoma (75.0\%). Promoter methylation of BRCA1, GSTP1, P16 ${ }^{\mathrm{INK} 4 \mathrm{~A}}, M G M T$, $P T E N, R A R \beta 2$ and $C C N D 2$ were measured. The frequency of hypermethylation in cancer tissues was 24.3, 31.4, 40.0, 27.1, 48.6, 55.7 and $67.1 \%$, respectively, whereas the frequency of hypermethylation in BBD tissues was 0.0, 0.0, 20.0, 25.0,40.0, 40.0 and $45.0 \%$, respectively. There were $8(11.4 \%)$ cases of hypermethylation in one gene, $17(24.3 \%)$ cases of hypermethylation in two genes, $14(20.0 \%)$ cases of hypermethylation in three genes, 17 (24.3\%) cases of hypermethylation in four genes, $6(8.6 \%)$ cases of hypermethylation in five genes, and $4(5.7 \%)$ cases of hypermethylation in six genes. Only four patients did not exhibit any hypermethylation in these seven genes. BRCAl $(24.3 \%$ in $\mathrm{BC}$ vs. $0.0 \%$ in $\mathrm{BBD} ; \mathrm{P}=0.034)$ and $G S T P 1$ ( $31.4 \%$ in $\mathrm{BC}$ vs. $0.0 \%$ in $\mathrm{BBD} ; \mathrm{P}=0.010)$ were significantly hypermethylated in $\mathrm{BC}$ as compared with $\mathrm{BBD}$ controls (Table II). Fig. 1 summarizes the methylation patterns of selected genes.

The sensitivity and specificity of each gene in distinguishing BC was calculated (Table III). The AUC for selected genes ranged from 0.511 to 0.657 . The sensitivity of each gene ranged from 24.3 to $67.1 \%$ and the specificity ranged from 55.0 to $100.0 \%$. Methylation was scored as 1 and unmethylation as 0 . The scores of the selected genes of the biomarker were totalled. When the combination of $B R C A I$ and GSTP1 was used, the AUC was 0.721 [95\% confidence interval (CI), 0.616-0.827; $\mathrm{P}=0.003$ ], with a sensitivity of $44.3 \%$ and a specificity of $100.0 \%$ at the cut-off point of 1 , which indicated hypermethylation in at least one gene (Table IV).When all seven candidate genes were used, the AUC was 0.741 (95\% CI, 0.631-0.850; $\mathrm{P}=0.001)$, with a sensitivity of $58.6 \%$ and a specificity of $80.0 \%$ when the cut-off
Table II. Methylation status of patients with $\mathrm{BC}$ and $\mathrm{BBD}$.

\begin{tabular}{lcccc}
\hline Genes & MU & BC, $\mathrm{n}(\%)$ & $\mathrm{BBD}, \mathrm{n}(\%)$ & P-value \\
\hline BRCA1 & $\mathrm{M}$ & $17(24.3)$ & $0(0.0)$ & 0.034 \\
& $\mathrm{U}$ & $53(75.7)$ & $20(100.0)$ & \\
GSTP1 & $\mathrm{M}$ & $22(31.4)$ & $0(0.0)$ & 0.010 \\
& $\mathrm{U}$ & $48(68.6)$ & $20(100.0)$ & \\
P16 ${ }^{\text {INK4A }}$ & $\mathrm{M}$ & $28(40.0)$ & $4(20.0)$ & 0.099 \\
& $\mathrm{U}$ & $42(60.0)$ & $16(80.0)$ & \\
MGMT & $\mathrm{M}$ & $19(27.1)$ & $5(25.0)$ & 0.848 \\
& $\mathrm{U}$ & $51(72.9)$ & $15(75.0)$ & \\
PTEN & $\mathrm{M}$ & $34(48.6)$ & $8(40.0)$ & 0.498 \\
& $\mathrm{U}$ & $36(51.4)$ & $12(60.0)$ & \\
RAR 22 & $\mathrm{M}$ & $39(55.7)$ & $8(40.0)$ & 0.215 \\
& $\mathrm{U}$ & $31(44.3)$ & $12(60.0)$ & \\
CCND2 & $\mathrm{M}$ & $47(67.1)$ & $9(45.0)$ & 0.072 \\
& $\mathrm{U}$ & $23(32.9)$ & $11(55.0)$ & \\
\hline
\end{tabular}

M, methylated; U, unmethylated; $\mathrm{BC}$, breast cancer; $\mathrm{BBD}$, benign breast disease; $B R C A 1$, breast cancer 1, early onset; DNA repair associated; GSTP1, glutathione S-transferase pi 1; P16 ${ }^{I N K 4 A}$, cyclin dependent kinase inhibitor 2A; MGMT, O-6-methylguanine-DNA methyltransferase; PTEN, phosphatase and tensin homolog; RAR 2 , retinoic acid receptor beta 2; CCND2, cyclin D2.

point was set at 3, which indicated hypermethylation in at least three genes (Table V). Fig. 2 illustrates the ROC curves of different combinations.

Association of methylation status and clinicopathological parameters. Table VI presents the methylation status of 
Table III. Diagnostic performance of candidate genes.

\begin{tabular}{|c|c|c|c|c|c|c|c|}
\hline Gene & $\begin{array}{c}\text { BC } \\
\text { pos./total }\end{array}$ & $\begin{array}{c}\text { BBD } \\
\text { pos./total }\end{array}$ & Sensitivity (\%) & Specificity (\%) & AUC & $95 \% \mathrm{CI}$ & P-value \\
\hline$B R C A l$ & $17 / 70$ & $0 / 20$ & 24.3 & 100.0 & 0.621 & $0.497-0.745$ & 0.099 \\
\hline GSTP1 & $22 / 70$ & $0 / 20$ & 31.4 & 100.0 & 0.657 & $0.540-0.775$ & 0.033 \\
\hline$P 16^{I N K 4 A}$ & $28 / 70$ & $4 / 20$ & 40.0 & 80.0 & 0.600 & $0.465-0.735$ & 0.174 \\
\hline$M G M T$ & $19 / 70$ & $5 / 20$ & 27.1 & 75.0 & 0.511 & $0.367-0.654$ & 0.884 \\
\hline PTEN & $34 / 70$ & $8 / 20$ & 48.6 & 60.0 & 0.543 & $0.400-0.686$ & 0.560 \\
\hline$R A R \beta 2$ & $39 / 70$ & $8 / 20$ & 55.7 & 60.0 & 0.579 & $0.437-0.720$ & 0.286 \\
\hline$C C N D 2$ & $47 / 70$ & $9 / 20$ & 67.1 & 55.0 & 0.611 & $0.468-0.754$ & 0.133 \\
\hline
\end{tabular}

BC, breast cancer; BBD, benign breast disease; AUC, area under the curve; CI, confidence interval; pos., positive; BRCA1, breast cancer 1, early onset; DNA repair associated; GSTP1, glutathione S-transferase pi 1; P16 INK4A , cyclin dependent kinase inhibitor 2A; MGMT, O-6methylguanine-DNA methyltransferase; PTEN, phosphatase and tensin homolog; RAR $\beta 2$, retinoic acid receptor beta 2; CCND2, cyclin D2.

Table IV. Combination of BRCAl and GSTPI for the diagnosis of breast cancer.

\begin{tabular}{lcccc}
\hline Cut-point & Sensitivity $(\%)$ & Specificity $(\%)$ & Correctly classified (\%) & LR+ \\
\hline$\geq 0$ & 100.0 & 0.0 & 77.8 & - \\
$\geq 1$ & 44.3 & 100.0 & 56.7 & 0.00 \\
$\geq 2$ & 11.4 & 100.0 & 31.1 & - \\
$>2$ & 0.0 & 100.0 & 22.2 & - \\
\hline
\end{tabular}

LR, likelihood ratio.

Table V. Combination of seven candidate genes for the diagnosis of breast cancer.

\begin{tabular}{lcccc}
\hline Cut-point & Sensitivity $(\%)$ & Specificity $(\%)$ & Correctly classified (\%) & LR+ \\
\hline$\geq 0$ & 100.0 & 0.0 & 77.8 & 1.00 \\
$\geq 1$ & 94.3 & 10.0 & 75.6 & 1.05 \\
$\geq 2$ & 82.9 & 45.0 & 74.4 & 0.57 \\
$\geq 3$ & 58.6 & 80.0 & 63.3 & 0.38 \\
$\geq 4$ & 38.6 & 95.0 & 51.1 & 0.51 \\
$\geq 5$ & 14.3 & 100.0 & 33.3 & 2.93 \\
$\geq 6$ & 5.7 & 100.0 & 26.7 & -7.71 \\
$>6$ & 0.0 & 100.0 & 22.2 & - \\
\hline
\end{tabular}

LR, likelihood ratio.

patients included in the present study stratified by age, tumor size, histologic type, clinical stage, lymph node metastases, menopausal status and the expression levels of estrogen receptor $(E R)$, progesterone receptor $(P R)$, human epidermal growth factor receptor 2 (HER2) and $P 53$ in cancerous tissues. Hypermethylation of BRCAI was demonstrated to be significantly more frequent in patients with lymph node metastasis $(\mathrm{P}=0.025)$. Hypermethylation of $P 16^{\mathrm{INK} 4 \mathrm{~A}}$ was significantly associated with age $(\mathrm{P}=0.015)$, menopausal status $(\mathrm{P}=0.003)$ and $P 53$ expression $(\mathrm{P}=0.011)$. Hypermethylation of PTEN was significantly associated with menopausal status $(\mathrm{P}=0.027)$.
$R A R \beta 2$ hypermethylation was significantly more common in $E R$-negative $(\mathrm{P}=0.002), P R$-negative $(\mathrm{P}<0.001)$ and $P 53$-positive tumors $(\mathrm{P}=0.020)$.

Association between gene methylation and protein expression. Immunohistochemical analysis was performed to assess the expression of BRCA1 and GSTP1. With the increase of methylation frequency, protein expression decreased significantly $(\mathrm{P}<0.05$; Table VII). Immunohistochemical staining results together with the promoter methylation status of BRCAl and GSTPI are shown in Fig. 3. 


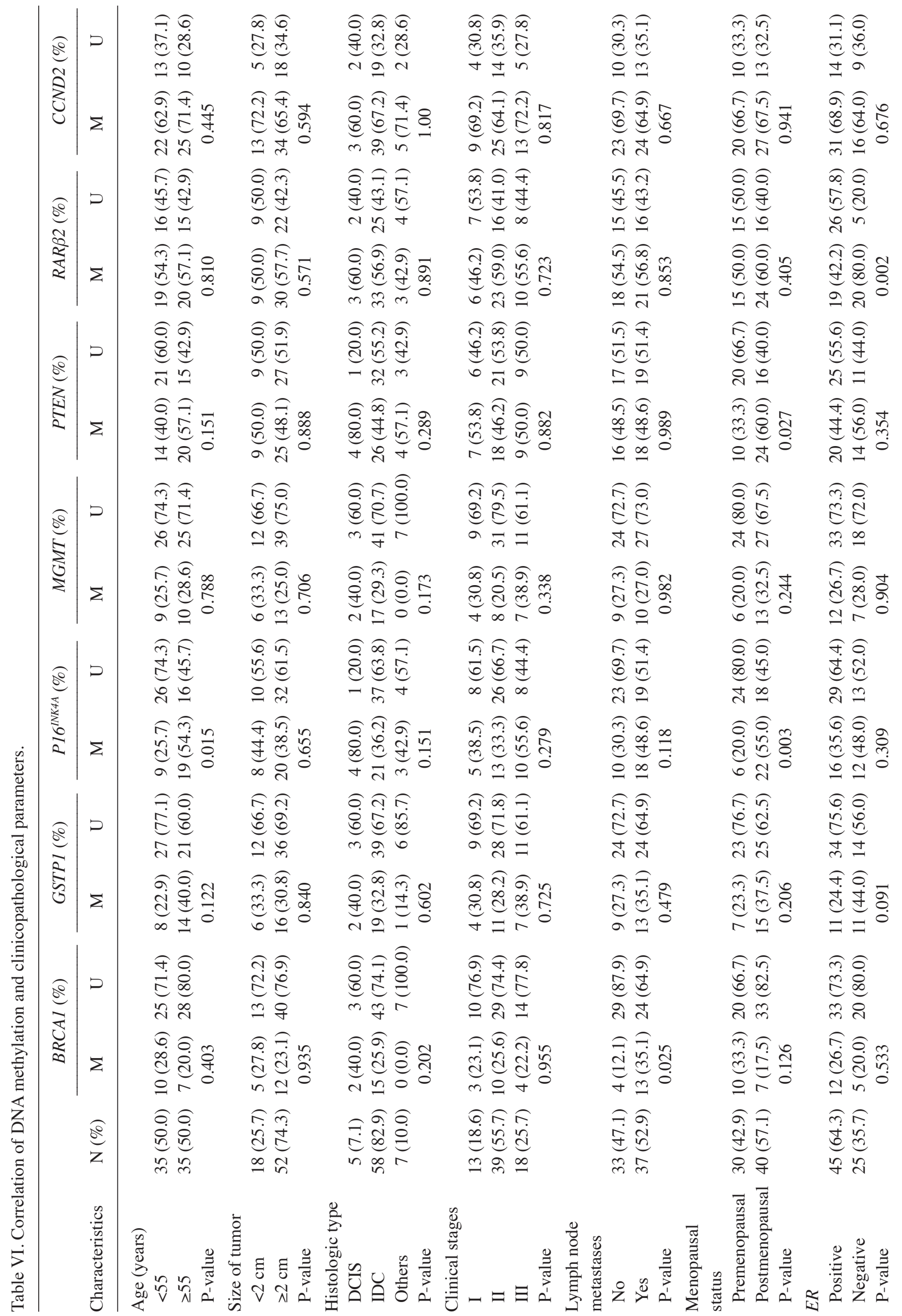




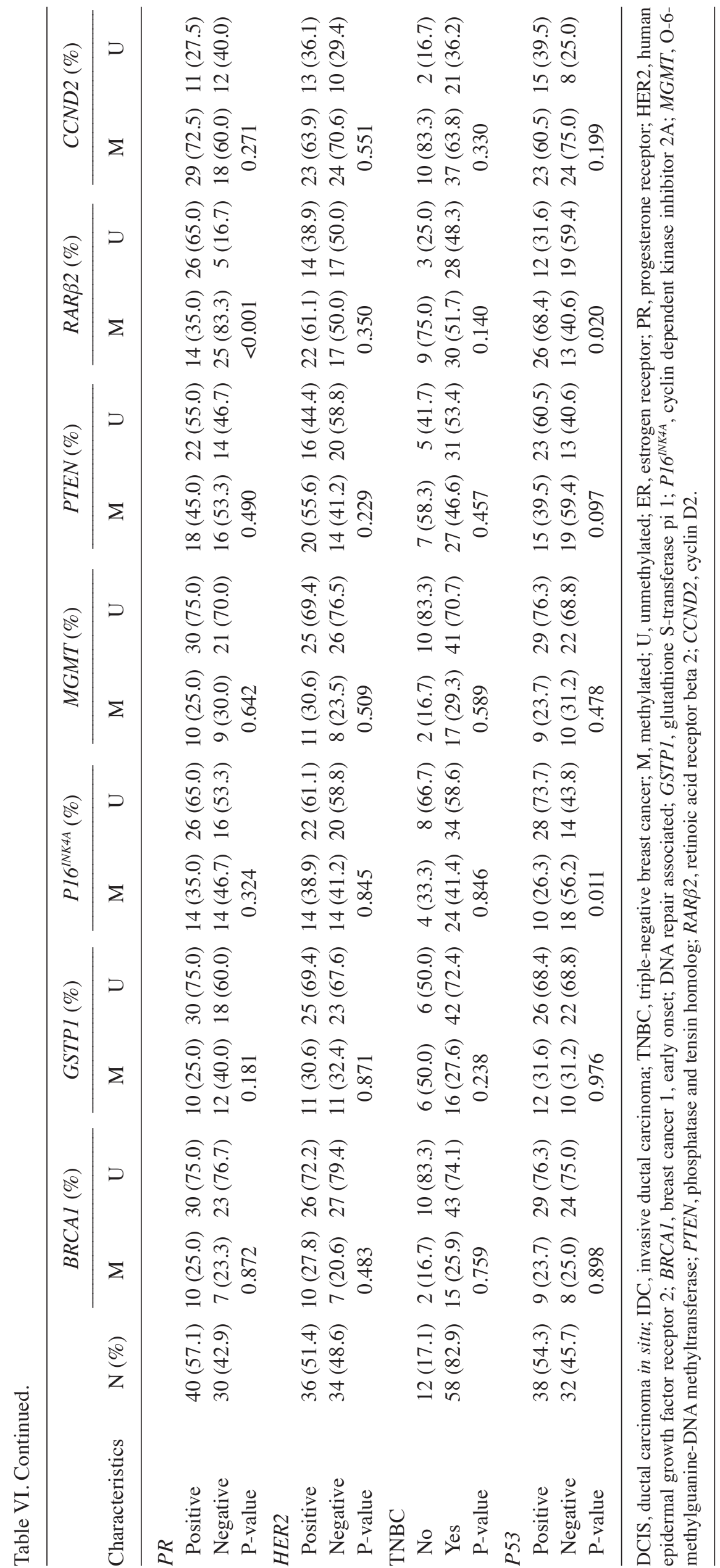


Table VII. Association between methylation and protein expression.

\begin{tabular}{lcclll}
\hline & \multicolumn{2}{c}{$B R C A 1, \mathrm{n}(\%)$} & & \multicolumn{2}{c}{$G S T P 1, \mathrm{n}(\%)$} \\
\cline { 2 - 3 } \cline { 5 - 6 } Gene expression & $\mathrm{M}$ & $\mathrm{U}$ & & $\mathrm{M}$ & $\mathrm{U}$ \\
\hline Negative & $0(0.0)$ & $0(0.0)$ & & $9(100.0)$ & $0(0.0)$ \\
Weak & $14(70.0)$ & $6(30.0)$ & & $9(64.3)$ & $5(35.7)$ \\
Moderate & $3(30.0)$ & $7(70.0)$ & & $4(50.0)$ & $4(50.0)$ \\
Strong & $0(0.0)$ & $2(100.0)$ & & $0(0.0)$ & $1(100.0)$ \\
P-value for trend & \multicolumn{2}{c}{0.011} & & \multicolumn{2}{c}{0.008}
\end{tabular}

M, methylated; U, unmethylated; $B R C A 1$, breast cancer 1 , early onset; DNA repair associated; GSTP1, glutathione S-transferase pi 1.

\section{Discussion}

Tumor biomarker tests are critical to the implementation of personalized medicine for patients at risk for or affected by BC. Newly developed genome-wide methods have revealed multiple epigenetic alterations that contribute to the carcinogenesis of BC (29). In the present study, seven cancer-related genes were selected and their methylation status was compared between 70 patients with sporadic BC and 20 controls with $\mathrm{BBD}$. The methylation frequencies of these candidate genes were consistent with previous published articles (14,23,30-33). As expected, hypermethylation of these cancer-related genes was more frequent in cancer tissues as compared with BBD. Moreover, immunohistochemical analysis demonstrated that a significant reduction of gene expression is related to promoter methylation.

$B R C A 1$, which is a typical tumor suppressor gene, contributes to the regulation of transcriptional activation, DNA repair, apoptosis, cell-cycle checkpoint control and chromosomal remodeling (28). A previous meta-analysis has provided evidence that $B R C A 1$ methylation is associated with the poor survival of patients with BC (34). The present study reported that hypermethylation of the BRCAI gene promoter was present in $24.3 \%$ of patients with $\mathrm{BC}$, which was significantly associated with distant metastasis. This result led us to hypothesize that hypermethylation of the BRCAl gene promoter seemed to confer an advantage for tumors cells invasion, and may be used as a biomarker of advanced $\mathrm{BC}$. The present study results demonstrated that $B R C A 1$ expression was significantly decreased in patients with BRCAl hypermethylation, which was consistent with the results reported by Shilpa et al (35). No methylation of $B R C A 1$ gene was detected in $\mathrm{BBD}$ patients.

GSTP1, which has an important role in the detoxification of toxic substances, is a phase II metabolic enzyme. The silencing of phase II metabolic enzymes by promoter methylation has been suggested to be implicated in the pathogenesis of BC (36). In the present study, the frequency of GSTPI methylation in BBD tissues was 0\%. GSTP1 protein expression was found to be absent or markedly decreased in the majority of the GSTP1 methylated tumors, suggesting that epigenetic gene silencing in these tumors may interfere directly with the

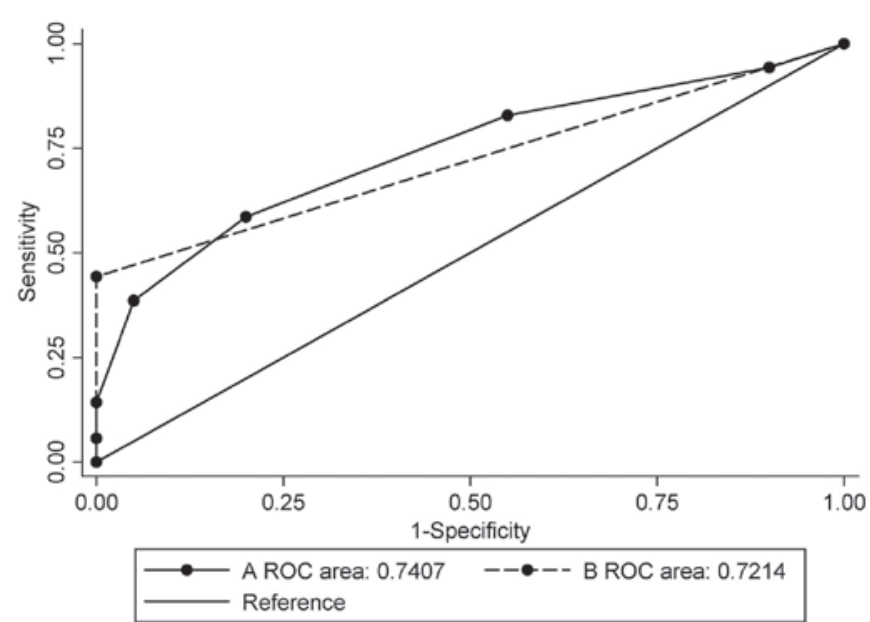

Figure 2. ROC analysis of DNA methylation. (A) ROC curve for the combination of seven candidate genes; (B) ROC curve for the combination of breast cancer 1 , early onset; DNA repair associated and glutathione S-transferase pi 1. ROC, receiver operating characteristic.

binding of sequence-specific transcription factors that would otherwise promote gene expression (37).

$P 16^{\mathrm{INK} 4 \mathrm{~A}}$ is a major target in human carcinogenesis. It is epigenetically silenced in various human tumors and the downregulation of $P 16^{\mathrm{INK} 4 \mathrm{~A}}$ protein has been reported in multiple cancers (38). In the present study, $P 16^{\mathrm{INK} 4 \mathrm{~A}}$ hypermethylation was found to be associated with patient's age at the diagnosis and menopausal status. This suggested that loss of $P 16^{\mathrm{INK} 4 \mathrm{~A}}$ expression through aberrant promoter methylation may occur more frequently in old women with BC (39). Moreover, it was observed that $P 53$ expression was associated with $P 16^{\mathrm{INK} 4 \mathrm{~A}}$ methylation status. A previous study has revealed that $P 16^{\mathrm{INK} 4 \mathrm{~A}}$ gene activity inversely modulated $p 53$ status and function in primary human mammary epithelial cells (40). Reduced levels of $P 16^{\text {INK4A }}$ protein stabilize $P 53$ protein through the inhibition of proteolytic degradation (40). Inactivation of $P 16^{\mathrm{INK} 4 \mathrm{~A}} /$ retinoblastoma and P53/P21 pathways via hypermethylation has been linked to critical telomere shortening, leading to genome instability and ultimately to BC formation (41). This may partly explain the association between $P 16^{\mathrm{INK} 4 \mathrm{~A}}$ methylation and $P 53$ expression.

$M G M T$ catalyzes the transfer of the methyl group from O6-methylguanine to a cysteine residue of its active site (42). Tumors with low levels of protein expression due to the epigenetic silencing of $M G M T$ in the promoter region have previously been examined (42). Consistent with the present findings, earlier studies have reported the frequency of $M G M T$ methylation ranging from 22 to $32 \%$ (43).

$C C N D 2$ belongs to a family of D-type cyclins (44). Previous studies revealed that high methylation levels of CCND2 caused deregulation of the G1/S checkpoint, and affected clinicopathologic features of tumor aggressiveness in BC (44). A study by Pu et al (45) reported that methylation of CCND2 (71\%) was higher in invasive BCs, which was consistent with the findings of the present study.

PTEN was the first recognized tumor suppressor with lipid phosphatase activity (46). Zhang et al (46) reported that PTEN hypermethylation was detected in $31.1 \%$ of $\mathrm{BC}$ cases, which was lower than the present results (48.6\%). Notably, the present 
A

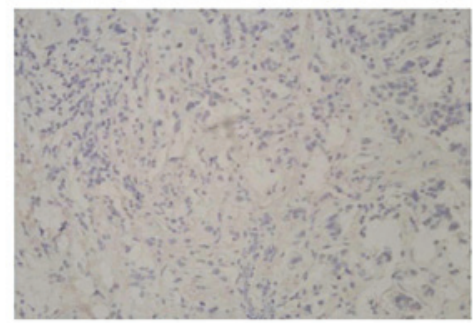

C

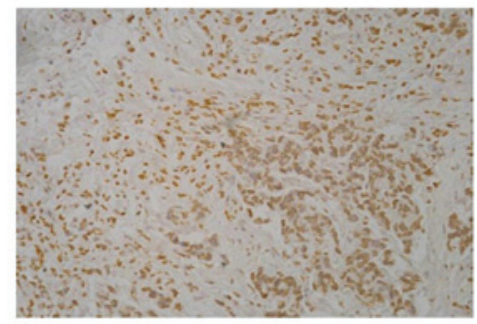

E

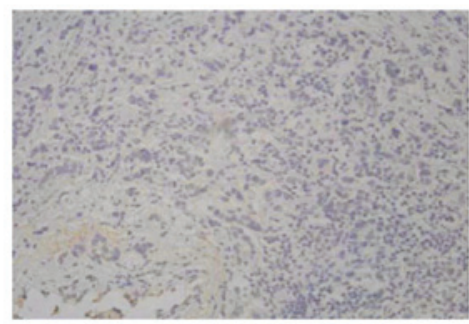

G

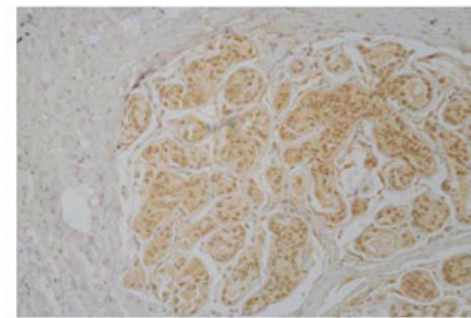

B

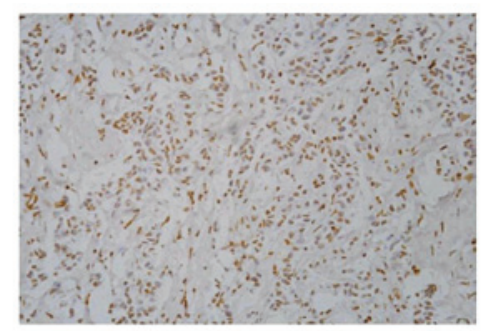

D

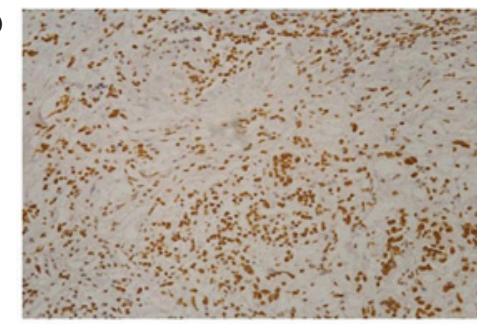

F

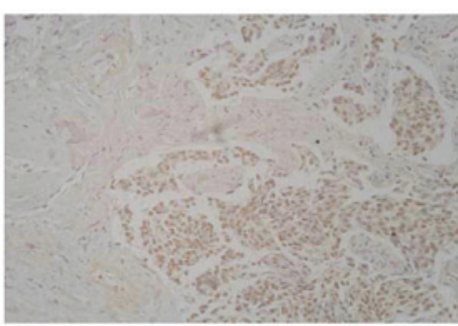

H

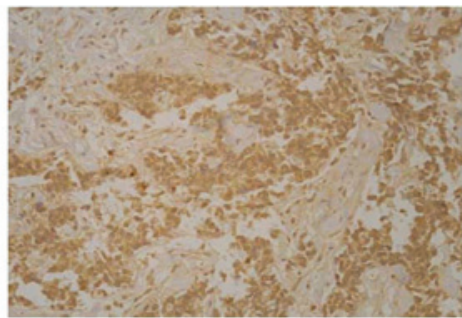

Figure 3. Immunohistochemical staining of BRCA1 and GSTP1. (A) BRCA1 negative; (B) tumor exhibiting weak staining; (C) tumor exhibiting moderate staining; (D) tumor exhibiting strong staining; (E) GSTP1 negative; (F) tumor exhibiting weak staining; (G) tumor exhibiting moderate staining; and (H) tumor exhibiting strong staining (magnification, x200). BRCA1, breast cancer 1, early onset; DNA repair associated; GSTP1, glutathione S-transferase pi 1.

study also found that PTEN methylation was more frequent in postmenopausal patients.

Retinoic acid, which has three subtypes $(\alpha, \beta$ and $\gamma)$, induces growth inhibition and apoptosis by regulating gene expression through its nuclear receptors (47). The human $R A R \beta$ gene has four isoforms ( $\beta 1, \beta 2, \beta 3$ and $\beta 4)$, with the $\beta 2$ isoform being the most abundant. The protein encoded by $R A R \beta 2$ functions in the inhibition of proliferation, apoptosis and senescence (48). Lee et al (49) demonstrated that $R A R \beta 2$ and the $P 53$ tumor suppressor gene inhibited oncogene-induced focus formation. Expression of HER2, ER and PR proteins are considered to be predictive markers for hormone therapy response in $\mathrm{BC}(20)$. The present study found that $R A R \beta 2$ was more frequently hypermethylated in $E R$-negative, $P R$-negative and $P 53$ positive cancer patients, suggesting an interlink between cancer-related genes.

Studies testing the ability of promoter methylation profiles to distinguish benign and malignant diseases have yielded conflicting results (17). A study that included women with invasive $\mathrm{BC}$, in situ $\mathrm{BC}$ and benign breast disease compared with healthy controls found that promoter methylation of three genes $(A P C$, Ras association domain family 1 isoform $\mathrm{A}$ and
$D A P K$ ) was detectable in DNA obtained from in situ lesions and invasive samples at all tumor stages (50). However, in another study, researchers found that fibroadenomas had patterns of methylation that were similar to those seen in $\mathrm{BC}$ cases (51). In the present study, hypermethylation was observed in some specific genes in patients with BBD, which was lower than that in $\mathrm{BC}$ cases, with a significantly different methylation rate in the genes of BRCA1 and GSTP1. When BRCA1 and GSTPI were combined, the specificity of diagnosing BC reached 100.0\%; however, the sensitivity was only $44.3 \%$. To achieve a more reliable gene panel, sensitivity and specificity were expected be enhanced by the addition of other genes that are frequently hypermethylated in BCs to the panel and a larger population.

The present study has some limitations. Firstly, the study protocol only focused on the aberrant DNA methylation of candidate genes. Other epigenetic traits, such as histone post-transcriptional modifications and non-coding RNAs, and genetic mutations are also critical for the spatio-temporal regulation of gene expression $(52,53)$. This may limit the diagnostic accuracy of biomarkers detected in this study. Secondly, due to the limitation of the MSP technology, only a few of $\mathrm{CpG}$ 
islands in the promoter region of genes were measured. The frequency of hypermethylation detected using MSP cannot fully reflect the methylation status of this gene. Therefore, to acquire a comprehensive understanding of DNA methylation status, more accurate and quantitative methods are required.

Promoter hypermethylation of BRCA1, GSTP1, P16 INK4A, $M G M T, P T E N, R A R \beta 2$ and CCND2 was frequently observed in $\mathrm{BC}$ and associated with various clinical pathological features. Hypermethylation of BRCA1 and GSTP1 was more common in cancerous tissues, which indicates these may be used as promising biomarkers for the diagnosis of $\mathrm{BC}$.

\section{Acknowledgements}

The present study was supported by the National Natural Science Foundation of China (grant no. 81172268), Key University Science Research Project of Jiangsu Province (grant no. 12KJA330001), Social Development Project in Jiangsu Province (grant no. BE2015694), Six Talent Peaks Project in Jiangsu Province (grant no. 2014-YY-023), and Priority Academic Program Development of Jiangsu Higher Education Institutions (grant no. PAAD).

\section{References}

1. WHO: Breast cancer: Prevention and control. Retrieved October 19, 2016 (http://www.who.int/cancer/detection/breastcancer/en/index1.html).

2. Radpour R, Barekati Z, Kohler C, Lv Q, Bürki N, Diesch C, Bitzer J, Zheng H, Schmid S and Zhong XY: Hypermethylation of tumor suppressor genes involved in critical regulatory pathways for developing a blood-based test in breast cancer. PLoS One 6: e16080, 2011.

3. Swedish Organised Service Screening Evaluation Group: Reduction in breast cancer mortality from the organised service screening with mammography: 2 . Validation with alternative analytic methods. Cancer Epidemiol Biomarkers Prev 15: 52-56, 2006.

4. Nelson HD, O'Meara ES, Kerlikowske K, Balch S and Miglioretti D: Factors associated with rates of false-positive and false-negative results from digital mammography screening: An analysis of registry data. Ann Intern Med 164: 226-235, 2016.

5. Njor SH, Hallas J, Schwartz W, Lynge E and Pedersen AT: Type of hormone therapy and risk of misclassification at mammography screening. Menopause 18: 171-177, 2011.

6. Baylin SB, Belinsky SA and Herman JG: Aberrant methylation of gene promoters in cancer-concepts, misconcepts, and promise. J Natl Cancer Inst 92: 1460-1461, 2000.

7. Jones PA and Laird PW: Cancer epigenetics comes of age. Nat Genet 21: 163-167, 1999.

8. Toh Y, Egashira A and Yamamoto M: Epigenetic alterations and their clinical implications in esophageal squamous cell carcinoma. Gen Thorac Cardiovasc Surg 61: 262-269, 2013.

9. Fang F, Turcan S, Rimner A, Kaufman A, Giri D, Morris LG, Shen R, Seshan V, Mo Q, Heguy A, et al: Breast cancer methylomes establish an epigenomic foundation for metastasis. Sci Transl Med 3: 75ra25, 2011.

10. Jones PA and Baylin SB: The epigenomics of cancer. Cell 128: 683-692, 2007

11. Cheol Kim D, Thorat MA, Lee MR, Cho SH, Vasiljević N, Scibior-Bentkowska D, Wu K, Ahmad AS, Duffy S, Cuzick JM and Lorincz AT: Quantitative DNA methylation and recurrence of breast cancer: A study of 30 candidate genes. Cancer Biomark 11: 75-88, 2012.

12. Pang JM, Deb S, Takano EA, Byrne DJ, Jene N, Boulghourjian A, Holliday A, Millar E, Lee CS, O'Toole SA, et al: Methylation profiling of ductal carcinoma in situ and its relationship to histopathological features. Breast Cancer Res 16: 423, 2014.

13. Brooks JD, Cairns P, Shore RE, Klein CB, Wirgin I, Afanasyeva Y and Zeleniuch-Jacquotte A: DNA methylation in pre-diagnostic serum samples of breast cancer cases: Results of a nested case-control study. Cancer Epidemiol 34: 717-723, 2010.
14. Fackler MJ, McVeigh M, Evron E, Garrett E, Mehrotra J, Polyak K, Sukumar S, Argani P.: DNA methylation of RASSF1A, HIN-1, RAR-beta, Cyclin D2 and Twist in in situ and invasive lobular breast carcinoma. Int J Cancer 107: 970-975, 2003.

15. Fackler MJ, McVeigh M, Mehrotra J, Blum MA, Lange J, Lapides A, Garrett E, Argani P, Sukumar S: Quantitative multiplex methylation-specific PCR assay for the detection of promoter hypermethylation in multiple genes in breast cancer. Cancer Res 64: 4442-4452, 2004.

16. Terry MB, McDonald JA, Wu HC, Eng S and Santella RM: Epigenetic biomarkers of breast cancer risk: Across the breast cancer prevention continuum. Adv Exp Med Biol 882: 33-68, 2016.

17. Brooks J, Cairns P and Zeleniuch-Jacquotte A: Promoter methylation and the detection of breast cancer. Cancer Causes Control 20: 1539-1550, 2009.

18. Sturgeon SR, Balasubramanian R, Schairer C, Muss HB, Ziegler RG and Arcaro KF: Detection of promoter methylation of tumor suppressor genes in serum DNA of breast cancer cases and benign breast disease controls. Epigenetics 7: 1258-1267, 2012.

19. Singletary SE and Connolly JL: Breast cancer staging: Working with the sixth edition of the AJCC Cancer Staging Manual. CA Cancer J Clin 56: 37-47, 2006.

20. Amara K, Trimeche M, Ziadi S, Laatiri A, Hachana M, Sriha B, Mokni M and Korbi S: Presence of simian virus 40 DNA sequences in diffuse large B-cell lymphomas in Tunisia correlates with aberrant promoter hypermethylation of multiple tumor suppressor genes. Int J Cancer 121: 2693-2702, 2007.

21. Baldwin RL, Nemeth E, Tran H, Shvartsman H, Cass I, Narod S and Karlan BY: BRCA1 promoter region hypermethylation in ovarian carcinoma: A population-based study. Cancer Res 60: 5329-5333, 2000

22. Pongtheerat T, Pakdeethai S, Purisa W, Chariyalertsak S and Petmitr S: Promoter methylation and genetic polymorphism of glutathione S-transferase P1 gene (GSTP1) in Thai breast- cancer patients. Asian Pac J Cancer Prev 12: 2731-2734, 2011.

23. Vallian S, Sedaghat M, Nassiri I and Frazmand A: Methylation status of p16 INK4A tumor suppressor gene in Iranian patients with sporadic breast cancer. J Cancer Res Clin Oncol 135: 991-996, 2009.

24. Ye C, Shrubsole MJ, Cai Q, Ness R, Grady WM, Smalley W, Cai H, Washington K and Zheng W: Promoter methylation status of the MGMT, hMLH1, and CDKN2Ap16 genes in non-neoplastic mucosa of patients with and without colorectal adenomas. Oncol Rep 16: 429-435, 2006.

25. Muñoz J, Inda MM, Lázcoz P, Zazpe I, Fan X, Alfaro J, Tuñón T, Rey JA and Castresana JS: Promoter methylation of RASSF1A associates to adult secondary glioblastomas and pediatric glioblastomas. ISRN Neurol 2012: 576578, 2012.

26. Karray-Chouayekh S, Trifa F, Khabir A, Boujelbane N, Sellami-Boudawara T, Daoud J, Frikha M, Jlidi R, Gargouri A and Mokdad-Gargouri R: Aberrant methylation of RASSF1A is associated with poor survival in Tunisian breast cancer patients. J Cancer Res Clin Oncol 136: 203-210, 2010.

27. Matsubayashi H, Sato N, Fukushima N, Yeo CJ, Walter KM, Brune K, Sahin F, Hruban RH and Goggins M: Methylation of cyclin D2 is observed frequently in pancreatic cancer but is also an age-related phenomenon in gastrointestinal tissues. Clin Cancer Res 9: 1446-1452, 2003.

28. Bai X, Fu Y, Xue H, Guo K, Song Z, Yu Z, Jia T, Yan Y, Zhao L, Mi X, et al: BRCA1 promoter hypermethylation in sporadic epithelial ovarian carcinoma: Association with low expression of BRCA1, improved survival and co-expression of DNA methyltransferases. Oncol Lett 7: 1088-1096, 2014.

29. Dworkin AM, Huang TH and Toland AE: Epigenetic alterations in the breast: Implications for breast cancer detection, prognosis and treatment. Semin Cancer Biol 19: 165-171, 2009.

30. Chen Y, Zhou J, Xu Y, Li Z, Wen X, Yao L, Xie Y and Deng D: BRCA1 promoter methylation associated with poor survival in Chinese patients with sporadic breast cancer. Cancer Sci 100: 1663-1667, 2009.

31. Shinozaki M, Hoon DS, Giuliano AE, Hansen NM, Wang HJ, Turner R and Taback B: Distinct hypermethylation profile of primary breast cancer is associated with sentinel lymph node metastasis. Clin Cancer Res 11: 2156-2162, 2005.

32. Sharma G, Mirza S, Parshad R, Srivastava A, Gupta SD, Pandya $\mathrm{P}$ and Ralhan R: Clinical significance of promoter hypermethylation of DNA repair genes in tumor and serum DNA in invasive ductal breast carcinoma patients. Life Sci 87: 83-91, 2010. 
33. Sadeq V, Isar N and Manoochehr T: Association of sporadic breast cancer with PTENMMAC1TEP1 promoter hypermethylation. Med Oncol 28: 420-423, 2011.

34. Wu L, Wang F, Xu R, Zhang S, Peng X, Feng Y, Wang J and $\mathrm{Lu}$ C: Promoter methylation of BRCA1 in the prognosis of breast cancer: A meta-analysis. Breast Cancer Res Treat 142: 619-627, 2013.

35. Shilpa V, Bhagat R, Premalata CS, Pallavi VR, Ramesh G and Krishnamoorthy L: BRCA1 promoter hypermethylation and protein expression in ovarian carcinoma-an Indian study. Tumour Biol 35: 4277-4284, 2014.

36. Esteller M, Corn PG, Urena JM, Gabrielson E, Baylin SB and Herman JG: Inactivation of glutathione S-transferase P1 gene by promoter hypermethylation in human neoplasia. Cancer Res 58: 4515-4518, 1998.

37. Ronneberg JA, Tost J, Solvang HK, Alnaes GI, Johansen FE, Brendeford EM, Yakhini Z, Gut IG, Lønning PE, Børresen-Dale AL, et al: GSTP1 promoter haplotypes affect DNA methylation levels and promoter activity in breast carcinomas. Cancer Res 68: 5562-5571, 2008.

38. Lee JJ, Ko E, Cho J, Park HY, Lee JE, Nam SJ, Kim DH and Cho EY: Methylation and immunoexpression of p16 (INK4a) tumor suppressor gene in primary breast cancer tissue and their quantitative p16 (INK4a) hypermethylation in plasma by real-time PCR. Korean J Pathol 46: 554-561, 2012.

39. Johnson KC, Koestler DC, Cheng C and Christensen BC: Age-related DNA methylation in normal breast tissue and its relationship with invasive breast tumor methylation. Epigenetics 9: 268-275, 2014

40. Zhang J, Pickering CR, Holst CR, Gauthier ML and Tlsty TD: p16INK4a modulates p53 in primary human mammary epithelial cells. Cancer Res 66: 10325-10331, 2006.

41. Radpour R, Barekati Z, Haghighi MM, Kohler C, Asadollahi R, Torbati PM, Holzgreve W and Zhong XY: Correlation of telomere length shortening with promoter methylation profile of $\mathrm{p} 16 \mathrm{Rb}$ and p53p21 pathways in breast cancer. Mod Pathol 23: 763-772, 2010.

42. Ingold B, Schraml P, Heppner FL and Moch H: Homogeneous MGMT immunoreactivity correlates with an unmethylated MGMT promoter status in brain metastases of various solid tumors. PLoS One 4: e4775, 2009.
43. Asiaf A, Ahmad ST, Malik AA, Aziz SA, Rasool Z, Masood A and Zargar MA: Protein expression and methylation of MGMT, a DNA repair gene and their correlation with clinicopathological parameters in invasive ductal carcinoma of the breast. Tumour Biol 36: 6485-6496, 2015.

44. Sharma G, Mirza S, Prasad CP, Srivastava A, Gupta SD and Ralhan R: Promoter hypermethylation of p16INK4A, p14ARF, CyclinD2 and Slit2 in serum and tumor DNA from breast cancer patients. Life Sci 80: 1873-1881, 2007.

45. Pu RT, Laitala LE, Alli PM, Fackler MJ, Sukumar S and Clark DP: Methylation profiling of benign and malignant breast lesions and its application to cytopathology. Mod Pathol 16: 1095-1101, 2003

46. Zhang HY, Liang F, Jia ZL, Song ST and Jiang ZF: Mutation, methylation and expression in breast cancer patients. Oncol Lett 6: 161-168, 2013.

47. Kim Y, Jin D, Lee BB, Cho EY, Han J, Shim YM and Kim DH: RARbeta2 hypermethylation is associated with poor recurrence-free survival in never-smokers with adenocarcinoma of the lung. Clinical Epigenetics 7: 32, 2015.

48. Tao MH, Shields PG, Nie J, Millen A, Ambrosone CB, Edge SB Krishnan SS, Marian C, Xie B, Winston J, et al: DNA hypermethylation and clinicopathological features in breast cancer: The Western New York exposures and breast cancer (WEB) study. Breast Cancer Res Treat 114: 559-568, 2009.

49. Lee X, Si SP, Tsou HC and Peacocke M: Cellular aging and transformation suppression: A role for retinoic acid receptor beta 2 . Exp Cell Res 218: 296-304, 1995.

50. Dulaimi E, Hillinck J, Ibanez de Caceres I, Al-Saleem T and Cairns P: Tumor suppressor gene promoter hypermethylation in serum of breast cancer patients. Clin Cancer Res 10: 6189-6193, 2004.

51. Cowin P, Rowlands TM and Hatsell SJ: Cadherins and catenins in breast cancer. Curr Opin Cell Biol 17: 499-508, 2005.

52. Falahi F, Sgro A and Blancafort P: Epigenome engineering in cancer: Fairytale or a realistic path to the clinic? Front Oncol 5: $22,2015$.

53. Connolly R and Stearns V: Epigenetics as a therapeutic target in breast cancer. J Mammary Gland Biol Neoplasia 17: 191-204, 2012. 